\section{Captive Patients}

Coercion, brain-washing, physical torture, and the threat of maltreatment have disgraced man's history since it was first recorded. But on at least two counts these violations of the human spirit seem peculiarly evil today. The first is that modern technology and psychological knowledge have given a much sharper edge to man's capacity for inhuman treatment of his fellow men. And secondly, though we cannot claim any moral superiority over our ancestors, the less ferocious struggle for mere existence that most of mankind now enjoys than he endured in earlier times makes deliberate cruelty seem the more barbarous by contrast. Torture of whatever kind must be utterly repugnant to anyone of humane feeling.

But the sad fact remains that humane feelings have often proved insufficient to prevent the commission of atrocities. In the sway of religious or political causes ordinary decency has been overwhelmed time and again in people who in other respects have seemed to be healthy, friendly, loyal, and even harmless members of the community. Vicious conduct is not confined to psychopaths though they are apt to be attracted to join in when circumstances are favourable. It is commonly sane fanatics and unthinking functionaries who lead the way. Unless this is appreciated it is hard to understand how attempts can be made to entangle medical men, even peripherally, in the maltreatment of captives.

It goes without saying that no medical man who continues to subscribe to the tenets of his calling could in any way become drawn into the torture of victims. Yet a recent report ${ }^{1}$ by a medical group under the auspices of Amnesty International claims "there is evidence that doctors, in various parts of the world, have participated in torture." Unfortunately it leaves this bleak and horrifying utterance unsubstantiated by any evidence of where or when the doctors acted thus. And the reader can only wonder whether it refers to the odd black sheep-the criminal or abnormal person to be found in any walk of life-or to doctors in some numbers in recent times. The report then goes on to recommend that a centre should be set up for collecting information about treatment of victims of torture and offering specialized treatment; that a clear statement should be made by medical authorities that participation in torture is no part of a doctor's duty and is contrary to universally agreed medical ethics; that representations should be made to British national medical organizations to change the Official Secrets Act so that doctors would have access to information about treatment of prisoners in military and civil confinement; and that medical committees at national, international, and multinational levels should investigate routinely individual complaints about the use of coercion and torture.

Clearly doctors already know that participation in torture is no part of their duty, and no British national medical organization has the power to change the Official Secrets Act. But despite what may perhaps without offence be called their naivety the Amnesty proposals do reinforce the reminder expressed in these columns last year ${ }^{2}$ of the doctor's ethical obligations to a captive in his medical care. The doctor's duty is to his patient, and in a more general sense he should be guided by these words from the World Medical Association's Declaration of Geneva: "I will maintain the utmost respect for human life from the time of conception; even under threat I will not use my medical knowledge contrary to the laws of humanity."

But though a doctor can recognize torture as readily as the next man, and knows he can take no part in it without betraying his profession as well as relapsing into barbarism, he can also be faced with obscure and confusing choices of conduct when he has to deal with captives. For prisoners of all kinds must have full medical facilities, yet they receive them in circumstances that may present a medical man with unfamiliar ethical problems. There is therefore much to be said for establishing a commission of medical men and women in this country to examine the matter thoroughly. From it may be expected to come a "clear statement" such as the Amnesty medical group asks for, but any statement made without a thorough study of the subtleties on the fringe of man's inhumanity to man would have difficulty in avoiding platitudes about the obvious atrocities at its core. Nor should an inquiry of this character be limited to Britain. It is surely a theme that should concern the World Medical Association, whose Declarations of Geneva in 1946 and of Helsinki in 1964 on medical ethics generally and the ethics of human experiments are valuable restatements in a modern form of traditional principles.

1 Lancet 1973, 2, 900.

2 British Medical fournal, 1972, 1, 761.

\section{Asbestos Hazard}

That the inhalation of asbestos dust can be hazardous was recognized at the turn of the century with the observation that pulmonary fibrosis followed prolonged occupational exposure to it. An association was later shown between asbestosis and bronchial carcinoma, and this was followed some years later by the observation ${ }^{1}$ that neighbourhood or community exposure as well as certain kinds of industrial exposure to asbestos can be followed by the development of mesothelioma, a malignant tumour arising in the pleura or peritoneum.

In Great Britain M. L. Newhouse and H. Thompson ${ }^{2}$ found an association between mesothelioma and living within a half-mile $(1 \mathrm{~km})$ of an asbestos factory in an urban area. A cohort study ${ }^{3}$ in the U.S.A. of a group of insulation workers with long-term but comparatively light exposure to asbestos showed a large increase in lung cancer, cases of pleural and peritoneal mesothelioma, and a small increase in some cancers of the alimentary tract. In that group the combination of asbestos exposure and cigarette smoking increased the risk of lung cancer 90-fold compared with non-smokers without occupational asbestos exposure. P. C. Elmes and M. J. C. Simpson ${ }^{4}$ found a high mortality from cancer of the lung and gastrointestinal tract, from mesothelioma, and from pulmonary fibrosis in a group of Belfast insulation workers. In a radiological study of a sample of naval dockyard workers, $3 \%$ were found to have abnormalities related to asbestos exposure, but it is worth noting that half of these had not themselves worked with asbestos and could be considered neighbourhood workers. In this study radiological abnormalities of the pleura were common, and their prognostic significance in relation to mesothelioma was queried. ${ }^{5}$ In a group of shipyard workers whose exposure to dust was monitored for 20 years and shown to be near the threshold limit value asbestosis first developed after 13 years' exposure. ${ }^{6}$ Restriction of lung volume and abnormalities of gas exchange were found to be the earliest signs of disease.?

In all epidemiological studies the message is the same: the inhalation of asbestos dust is dangerous. It may give rise to 
pulmonary fibrosis leading to respiratory insufficiency and death; carcinoma of the bronchus; mesothelioma of the pleura or peritoneum; and cancer of the gastrointestinal tract. The hazard appears to be a continuing one, and some risk exists outside the asbestos industry as well as within it. What is not yet sufficiently clear is how much exposure is required in terms of concentration, time, and pattern, to what forms of asbestos fibre, and what the characteristics are of those people who are particularly vulnerable to its ill effects.

Recently P. Enterline and colleagues, ${ }^{8}$ of Pittsburgh, attempted to assess exposure to asbestos dust in a cohort of over 1,300 retired men whose mortality was followed up during 1969. The average length of exposure to it was long, 25 years, and some men had very heavy exposure for a long period. Agecorrected lung cancer mortality rates at the highest level of dust exposure were found to be about three times as high as those at the lowest exposure level. The risk of dying from lung cancer sharply increased at exposures of between 100 and 200 million particles per cubic foot of air-years, and they did not find a direct relationship between exposure and cancer below 125. Analysis showed that both length of exposure and concentration of dust appeared to make independent and similar contributions. However, the difficulty of estimating the dust level with any precision for many different jobs and for years past can be readily appreciated.

These issues and others have now been considered in an important report by the Advisory Committee on Asbestos Cancers to the director of the International Agency for Research on Cancer. ${ }^{9}$ The report follows that produced by the Geographical Pathology Committee of the International Union against Cancer. ${ }^{10}$ The advisory committee was asked to report on the present evidence relating cancers to exposure to asbestos dust and to make recommendations for further research. The report should be studied by all interested in the role of the environment in the production of cancer. In brief, the committee found that there is evidence for a causal relationship but that the risk differs with type of fibre and nature of exposure. The evidence suggests that an excess risk of lung cancer is not detectable when the occupational exposure has been low, and, further, that such low occupational exposures are almost certainly greater than from general air pollution with asbestos. As to mesothelioma, it appears that all commercial types of asbestos may be responsible, but the risk is greatest with crocidolite and less with chrysotile.

The risk from neighbourhood air pollution relates to crocidolite mines and to factories using mixtures of asbestos fibres in conditions which existed many years ago. No excess risk from mesothelioma has been found in the neighbourhood of chrysotile and amosite mines. As regards other cancers, a small excess risk has been shown in occupational groups only. Existing evidence does not indicate any increased risk of cancer from asbestos fibres present in food, drink, or drug fluids. Nor is there any evidence to suggest that pulmonary fibrosis can be caused by asbestos fibres present in the general environment.

Measurements have shown that the amount of asbestos fibre in the lungs of population samples is very small compared with the amount in the lungs of people who have had occupational exposure. But important positive evidence comes from an accumulation of data showing that cigarette smoking enhances the risk of lung cancer in workers exposed to asbestos, and therefore these groups have especially strong reasons for giving up smoking. In contrast, there is no evidence to show that trace metals, waxes, or oils have any similar enhancing effect.

The recommendations made for further research cover a wide field. With the necessary standardization and co-operation answers to urgent problems relating to asbestos should be forthcoming. The committee has indicated those projects it considers rate high in priority.

1 Wagner, J. C., Sleggs, C. A., and Marchand, P., British fournal of Industrial Medicine, 1960, 17, 260.

Newhouse, M. L., and Thompson, H., British fournal of Industrial Medicine, 1965, 22, 261.

${ }^{3}$ Selikoff, I. J., Hammond, E. C., and Churg, J., fournal of the American Medical Association, 1968, 204, 106.

4 Elmes, P. C., and Simpson, M. J. C., British Fournal of Industrial Medicine, 1971, 28, 226.

${ }^{5}$ Harries, P. G., et al., British fournal of Industrial Medicine, 1972, 29, 274.

${ }^{6}$ Murphy, R. L. H., Ferris, B. G., Burgess, W. A., Worcester, J., and Gaensler, E. A., New England fournal of Medicine, 1971, 285, 1271.

${ }^{7}$ Murphy, R. L. H., et al., Archives of Environmental Health, 1972, 25, 253.

8 Enterline, P., DeCoufle, P., and Henderson, V., British fournal of Industrial Medicine, 1973, 30, 162.

dustrial Medicine, 1973, 30, 162.
British fournal of Industrial Medicine, 1973, 30, 180.

10 British fournal of Industrial Medicine, 1965, 22, 165.

\section{Post-intubation Granuloma}

It could be argued that all the advances in surgical technique of the past thirty years were made possible by the introduction of intratracheal anaesthesia in the 1930s. Further technical improvements have included different substances from which the intratracheal tubes are made, cuffing of the tubes for closed-circuit administration, the structure of gas cylinders, the mechanical delivery of gases in exact proportions, gases of a less lethal nature, and the provision of automatic controls and safety devices. The use of muscle relaxants and controlled mechanically produced respiratory movements followed almost logically. Thus long operations are made possible with little surgical shock and minimal general harm to the patient.

But there is always some price to pay, and one slightly unexpected sequel has been the occurrence, though rarely, of a post-intubation laryngeal granuloma. It is distinct from the lesion that may result from accidental laryngeal trauma during the actual introduction of the tube. This kind of injury can be almost anywhere in the larynx and is usually trivial, causing no permanent damage. Intubation granuloma, however, nearly always occurs on the vocal process of the arytenoid cartilage, which forms the posterior quarter of the total length of the vocal cord. When the patient is supine, the tube comes to lie in the posterior part of the larynx, with its weight resting on the arytenoid cartilages. An area of epithelium (possibly including the perichondrium) may therefore be subjected to friction or to pressure ischaemia and may slough. If the raw surface becomes infected, inflammatory granulation tissue forms, and when spontaneous healing is prevented, perhaps because of lowered vitality in an enfeebled patient, an indolent ulcer may develop, or more often, a localized tumour.

In view of the very large number of intratracheal anaesthetics given, intubation granulomas are rare. Possibly they are more likely to arise when the patient is breathing spontaneously, for then the active movements of the vocal cords could cause friction between the cartilaginous vocal process and the tube. The lesion would seem less likely to develop in an immobile larynx, when a muscle relaxant and controlled respiration are used. Some discussion of the question would be welcome.

Direct laryngoscopy under general anaesthesia and careful removal of the granuloma, under magnification if necessary, is the usual treatment, and it should not be followed by permanent hoarseness and certainly not by laryngeal stenosis. A. Marshak 